\title{
COMPARAÇÃO ENTRE POTENCIAIS E EFETIVOS DOADORES DE CÓRNEA NO HOSPITAL UNIVERSITÁRIO EVANGÉLICO DE CURITIBA
}

\author{
Comparison between potential and effective cornea donors at the \\ Evangelic University Hospital of Curitiba
}

Ilana Barrichello Torres, Mariana Sponholz Araujo, Manuela Fiorese Benites, Hamilton Moreira

\begin{abstract}
RESUMO
Objetivo: Quantificar os potenciais doadores de córnea no Hospital Universitário Evangélico de Curitiba e comparar com os reais doadores. Separá-los conforme as unidades hospitalares onde foram atendidos. Verificar as principais causas base de óbito dos mesmos. Na impossibilidade de doação, evidenciar os critérios de exclusão mais prevalentes. Métodos: Estudo descritivo retrospectivo, realizado a partir da revisão de prontuários e atestados de óbito dos falecimentos ocorridos entre abril e julho de 2006 no Hospital Universitário Evangélico de Curitiba. Levantamento dos critérios de exclusão para doação, analisando: causa "mortis" e causa base do óbito, entre outros parâmetros. Resultados: Foram analisados 516 prontuários. Natimortos, recém-nascidos até dois anos e pacientes não identificados foram excluídos, totalizando uma amostra de 466 pacientes. Desses, 302 (64,8\%) foram considerados potenciais doadores, 164 (35,2\%) não-doadores. Dentre os 302 potenciais doadores houve apenas duas doações. Esse número representa $0,7 \%$ das possíveis doações. A principal causa base de óbito foi neoplasia maligna (29,8\%). A maioria dos potenciais doadores foi a óbito no Pronto Socorro (22,2\%), seguido por: UTI geral (10,5\%). Os critérios de exclusão identificados foram: Septicemia (87,2\%), linfoma ativo disseminado (4,3\%), leucemia (3,7\%), morte por causa desconhecida (3,0\%), encefalopatia viral ativa $(1,2 \%)$ e hepatite $\mathrm{C}(0,6 \%)$. Conclusão: Quando comparado ao número de potenciais doadores, o número efetivo de doações de córneas é muito pequeno. O setor de maior prevalência de potenciais doadores foi o Pronto Socorro. A principal causa base de óbito dos mesmos foi neoplasia. A maior causa de exclusão de potenciais doadores foi septicemia.
\end{abstract}

Descritores: Doadores de Tecidos, Transplante, Causa da Morte, Bancos de Olhos, Córnea.

\section{Instituição:}

Trabalho realizado no Departamento de Oftalmologia do Hospital Universitário Evangélico de Curitiba - Curitiba - PR.

\section{Correspondência:}

Mariana Sponholz Araujo

Rua Antônio Pietruza, № 266, apto. 181 - Portão

CEP: 80 610-320 - Curitiba- PR

Tel: 55 41- 3077-6442

E-mail: mari_sponholz@yahoo.com.br

Recebido em: 18.01.2007
Aceito em: 31.01 .2007

\section{INTRODUÇÃo}

Um dos procedimentos cirúrgicos mais importantes da oftalmologia é o transplante de córnea, uma vez que a recuperação da capacidade visual de um indivíduo é de extrema importância para sua inserção na sociedade moderna. ${ }^{1}$

O transplante de córnea, na maior parte das vezes, é indicado para a melhora da acuidade visual em patologias tais como ceratocone, ceratopatia bolhosa do pseudofácico, distrofias, degenerações e cicatrizes. Também pode ser indicado com finalidade tectônica para restaurar ou preservar a integridade corneana em olhos com alterações estruturais como afinamento estromal e descemetoceles. Além de ter indicação terapêutica na remoção de tecido corneano infectado que não responde à antibioticoterapia, ou até mesmo por motivos estéticos. ${ }^{2}$

A ceratoplastia penetrante tem tido sua indicação ampliada nos últimos 30 anos $^{3,4}$ devido a um aumento da faixa etária da população, melhor seleção do tecido doador e novas técnicas operatórias. ${ }^{5}$ Houve também avanços nas técnicas relacionadas aos Bancos de Olhos, processamento de órgãos, avaliação e conservação das córneas.

Tudo isso contribuiu para que o transplante de córnea hoje seja a modalidade mais comum de transplante de tecidos. ${ }^{6,7}$ Esse 
aumento só não foi ainda maior em decorrência do número limitado de doações. ${ }^{6,8,9}$

Embora o número de transplantes de córnea no Brasil tenha aumentado gradativamente ano após ano, havendo 8713 transplantes de córneas em 2005 contra 10124 em 2006, muitas pessoas ainda aguardam por córneas em lista de espera. ${ }^{10} \mathrm{O}$ mesmo crescimento acontece no Paraná, que, em 2006 realizou 618 transplantes de córnea, superando os 466 de 2005. ${ }^{11}$

Em 2006, constavam na lista do Brasil, 24549 pacientes, sendo que só no estado do Paraná esse número era de 1459. Para esse mesmo período, o tempo de espera era de aproximadamente um ano e seis meses. ${ }^{12}$

A retirada das córneas pode ser feita de 6 até 24 horas $^{13}$ após a parada cardíaca (quando o corpo é refrigerado). O procedimento pode ser realizado fora de ambiente hospitalar (necrotério, casa do doador). O tempo máximo de preservação extracorpórea da córnea é de 14 dias. Não há limite de idade para a doação, desde que seja realizada uma avaliação prévia da córnea, e é importante destacar que a remoção das córneas não acarreta efeito estético indesejável no doador. ${ }^{11}$

A retirada da córnea só pode ser realizada após autorização da família do doador cadáver (por escrito). Em seguida, a doação é notificada à Central de Transplante do Estado (CNCDO). ${ }^{11}$

A equipe de retirada do Banco de Olhos local faz a captação das córneas e as encaminha para a Central Estadual de Transplantes, juntamente com duas amostras de sangue, cuja finalidade é a realização dos exames sorológicos de rotina.

As córneas são mantidas em meio específico de conservação a $4^{\circ} \mathrm{C}$ e, caso liberadas para transplante, são distribuídas pela Central. ${ }^{11}$

$\mathrm{Na}$ literatura, existem contra-indicações para o uso do tecido corneano. ${ }^{13,14,15}$

O Hospital Universitário Evangélico de Curitiba não dispõe de um banco de dados com informações a respeito dos potenciais doadores. Esses dados seriam úteis para conhecer melhor a realidade do serviço, de acordo com as diferentes unidades hospitalares. Com tais informações, seria possível o desenvolvimento de ações direcionadas, para que número de doações de córnea aumentasse, diminuindo assim a fila de espera pelo transplante.

\section{OBJETIVOS}

Quantificar os potenciais doadores de córnea dentre os óbitos ocorridos no Hospital Universitário Evangélico de Curitiba.

Comparar com o número de reais doadores.

Verificar as principais causas base de óbito entre os mesmos.

Separá-los de acordo com a unidade hospitalar em que foram atendidos.

Nos casos de impossibilidade da doação, evidenciar quais foram os critérios de exclusão mais prevalentes.

\section{MÉTODOS}

Este trabalho compõe-se de um estudo descritivo retrospectivo. A pesquisa abrangeu um levantamento estatístico do número de potenciais doadores de córnea dentre os óbitos ocorridos no período de 07 de abril a 07 de julho de 2006 no Hospital Universitário Evangélico de Curitiba.
O estudo foi realizado através do levantamento dos critérios de exclusão de possíveis doadores. Os dados analisados incluem: número do prontuário do paciente, causa "mortis", causa base do óbito, comorbidades e unidade hospitalar onde ele estava sendo atendido quando da ocorrência do óbito.

Esse levantamento foi baseado nos prontuários e atestados de óbito dos falecidos durante o período já citado. Foram considerados não-doadores aqueles pacientes que apresentaram algum critério de exclusão conforme a Resolução - RDC no 347 da ANVISA, de 02 de dezembro de 2003 publicado no D.O.U de 03/12/200313, que regulamenta os critérios que legalmente todos os Bancos de Olhos do Brasil devem seguir. Em seguida, os pacientes considerados nãodoadores, foram separados de acordo com o motivo da exclusão.

Os critérios de exclusão são: morte por causa desconhecida, doença neurológica de caráter indeterminado, doença de CreutzfeldtJacob, pan-encefalite esclerosante subaguda, leucoencefalopatia multifocal progressiva, encefalopatia viral ativa, encefalite de origem desconhecia, encefalopatia progressiva, rubéola congênita, Síndrome de Reye, septicemia, endocardite bacteriana ou fúngica ativa, hepatite viral aguda, soropositividade para hepatite B e C, $\mathrm{HIV}+$, encefalite subaguda por citomegalovírus, raiva, leucemias, linfomas ativos disseminados, receptores de hormônio do crescimento derivado da pituitária humana (durante os anos de 1963-1985).

Além de pacientes portadores de doenças intrínsecas oculares (tumor maligno do segmento anterior, adenocarcinoma no olho, retinoblastoma, conjuntivite, ceratite, esclerite, irite, uveíte, vitreíte, coroidite, retinite, cicatriz central na córnea, ceratocone, ceratoglobo), ou submetidos à cirurgia intra-ocular ou do segmento anterior, procedimentos refrativos corneanos, ceratotomia radial, inserções lamelares ou fotoablação por laser.

Os demais pacientes foram considerados potenciais doadores e discriminados de acordo com a unidade hospitalar onde estavam sendo atendidos.

Posteriormente, através de contato com a Central de Transplantes do Paraná, foram obtidos dados referentes ao transplante de córneas no período estudado, incluindo o número de reais doadores.

\section{RESULTADOS}

Foram analisados 516 prontuários. Natimortos, recém-nascidos de até dois anos de idade e pacientes não identificados foram excluídos, totalizando uma amostra de 466 pacientes. Desses, 302 $(64,8 \%)$ foram considerados potencias doadores e $164(35,2 \%)$ não doadores.

De acordo com registros da Central de Transplantes do Paraná, dentre os 302 potenciais doadores houve duas doações de córneas efetivas no período estudado. Esse número representa $0,7 \%$ de doações.

As principais causas base de óbito dos potenciais doadores foram neoplasias malignas e afecções cardíacas, entre outras. (Tabela 1)

Dentre as causas de origem cardíaca, destaca-se o infarto agudo do miocárdio com uma porcentagem de $7,3 \%$ de todas as causas base de óbito. Em relação às afecções pulmonares, a mais prevalente foi a pneumonia (11,6\%).

A maioria dos potenciais doadores foi a óbito no Pronto Socorro, seguido por: UTI geral. (Tabela 2)

Foi encontrada uma série de causas de exclusão de doadores. (Figura 
1) A principal causa foi septicemia. Também houve dois casos de infecção pelo vírus HIV que ocorreram concomitantemente com septicemia sendo incluídos estatisticamente nesse critério.

\section{DISCUSSÃO}

O transplante de córnea constitui uma alternativa terapêutica cada vez melhor para grande parte das doenças corneanas. No entanto, $o$

Tabela 1: Distribuição dos potenciais doadores segundo a causa base de mortes

\begin{tabular}{lcc}
\hline Causa base de morte & \multicolumn{2}{c}{ Doadores } \\
\cline { 2 - 3 } & $N^{0}$ Absoluto & Percentual \\
\hline Neoplasias malignas & 90 & 29,8 \\
Afecções cardíacas & 46 & 15,2 \\
Afecções pulmonares & 44 & 14,6 \\
Acidentes vasculares encefálicos & 40 & 13,2 \\
Politrauma & 32 & 10,6 \\
Doenças gastrintestinais & 15 & 5,0 \\
FAF* e FAB† & 9 & 3,0 \\
Grandes queimados & 6 & 2,0 \\
Outras causas & 20 & 6,6 \\
\hline
\end{tabular}

${ }^{\star}$ FAF: Ferida por arma de fogo

tFAB: Ferida por arma branca

Tabela 2: Distribuição dos potenciais doadores segundo a unidade hospitalar em que estavam sendo atendidos

\begin{tabular}{|c|c|c|}
\hline \multirow[t]{2}{*}{ Unidade hospitalar } & \multicolumn{2}{|c|}{ Potenciais doadores } \\
\hline & $\mathrm{N}^{0}$ Absoluto & Percentual \\
\hline Pronto Socorro & 67 & 22,2 \\
\hline UTI Geral & 32 & 10,5 \\
\hline Neurologia e Neurocirurgia & 31 & 10,3 \\
\hline Clínica Médica & 31 & 10,3 \\
\hline Clínica Cirúrgica e Centro Cirúrgico Geral & 30 & 9,9 \\
\hline Oncologia & 29 & 9,6 \\
\hline UTI Coronariana & 18 & 6,0 \\
\hline Domicílio & 15 & 5,0 \\
\hline Convênios & 14 & 4,6 \\
\hline Angiologia & 6 & 2,0 \\
\hline Ginecologia e Obstetrícia & 6 & 2,0 \\
\hline Plástica/Queimados & 6 & 2,0 \\
\hline Nefrologia & 3 & 1,0 \\
\hline Cardiologia & 3 & 1,0 \\
\hline Ortopedia & 3 & 1,0 \\
\hline Hematologia & 2 & 0,7 \\
\hline Urologia & 2 & 0,7 \\
\hline Centro Cirúrgico Obstétrico & 1 & 0,3 \\
\hline Pneumologia & 1 & 0,3 \\
\hline Hemodiálise & 1 & 0,3 \\
\hline Hemodinâmica & 1 & 0,3 \\
\hline
\end{tabular}

Figura 1: Causas de exclusão de potenciais doadores

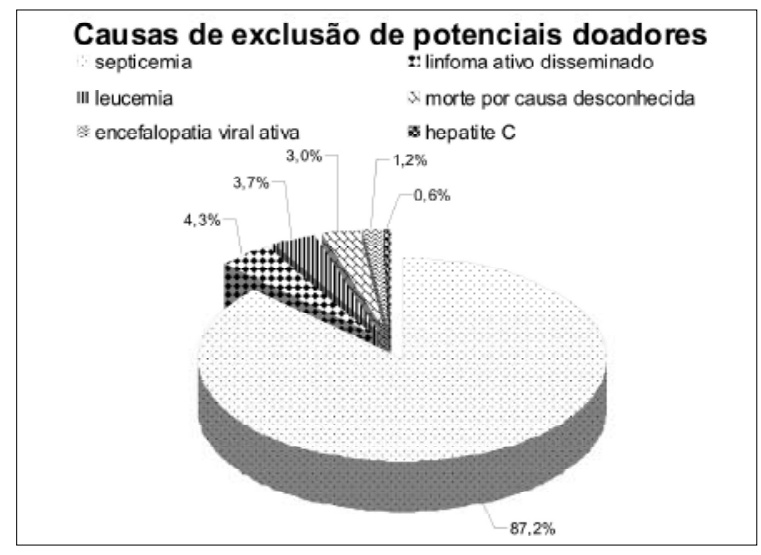

número de doações de córnea está aquém do necessário. ${ }^{8,9,16}$ Nesta pesquisa, apenas quatro córneas (dois doadores) foram captadas durante o período de estudo.

Houve 302 potenciais doadores (604 córneas) em três meses de estudo, o que, transpondo para um ano, resultaria em um total de 2416 córneas desperdiçadas, representando uma redução significativa na fila de espera do Paraná para esse tipo de transplante.

O número de 302 potenciais doadores representa $64,8 \%$ do total da amostra analisada, inferior aos 76,5\% encontrados na literatura, ${ }^{17}$ porém, significativamente superior aos $36,9 \%$ encontrados em outro estudo semelhante. ${ }^{18}$

No primeiro estudo acima citado, ${ }^{17}$ foram considerados nãodoadores $23,5 \%$ da amostra enquanto que no trabalho atual foram encontrados 31,8\%. Em ambas as pesquisas, a maior causa de exclusão foi septicemia; no entanto, no presente estudo houve uma prevalência de $87,2 \%$ dessa causa em contraste com os $23,5 \%$ encontrados na literatura. ${ }^{17}$ Houve concordância em relação à segunda causa, que foi linfoma ativo disseminado e leucemia. A porcentagem aqui encontrada foi de $7,9 \%$, enquanto que na literatura foi de $24,8 \%{ }^{17}$

Em contraste com esses valores, a principal causa de exclusão de doadores encontrada por outros autores ${ }^{18}$ foi remoção do cadáver do hospital e aplicação precoce de métodos de conservação do cadáver (16,6\%). Embora essas situações não sejam descritas como contra-indicações à doação de córneas, no estudo acima citado, que foi realizado prospectivamente, foram fatores que inviabilizaram a coleta das córneas. As seguintes maiores causas de exclusão, segundo este mesmo trabalho foram neoplasia e leucocitose $(13,3 \%) .{ }^{18}$ Isso se justifica pela exclusão de pacientes com septicemia e com idade superior a 80 anos da amostra desse estudo.

A RDC 347 da Anvisa ${ }^{13}$ não considera neoplasia e leucocitose critérios de exclusão para doação da córnea, e, portanto, não foram usados no presente trabalho. O motivo pelo qual tal estudo utilizou esses parâmetros diferenciados não está explícito, uma vez que os critérios de exclusão utilizados no mesmo não foram especificados.

Da mesma forma, em relação à idade para doação de córneas, entende-se que recém-nascidos menores de dois anos de idade não devem ser considerados doadores, pois suas córneas são evitadas para a finalidade óptica devido ao alto risco de ectasia e de indução 
de alto grau de miopia no receptor. Admite-se que a partir dos dois anos de idade, todas as córneas são passíveis de transplante e devem ser coletadas, especialmente se considerarmos os atuais avanços nas técnicas de transplante lamelar. ${ }^{19}$

No que concerne ao limite superior de idade, o presente estudo aceitou como doadores inclusive pacientes maiores de 70 anos, já que existem trabalhos mostrando que quando a contagem endotelial é satisfatória e o armazenamento é realizado da maneira correta, não importa a idade do doador. ${ }^{20}$

Com relação à causa base de morte, a literatura cita que 36,3\% dos falecimentos foram decorrentes de politrauma, seguidos diretamente pelas alterações do aparelho vascular (34\%). ${ }^{21}$ Isso difere do atual estudo em que a principal causa base foram as neoplasias malignas $(29,8 \%)$ e politrauma obteve uma porcentagem mais modesta $(10,6 \%)$.

O número de potenciais doadores encontrados na presente pesquisa em unidade de terapia intensiva, considerando-se UTI geral e UTI coronariana, foi de $16,5 \%$. Esse dado contrasta com a literatura pesquisada, onde cerca de $87 \%$ dos potenciais doadores de córnea encontravam-se em unidades de terapia intensiva. ${ }^{22}$ Segundo autores, isso também é verdadeiro para os demais doadores de órgãos que, em $95 \%$ dos casos, foram a óbito em UTI. ${ }^{23}$ Neste trabalho, o maior número de potenciais doadores estava sendo atendido em Pronto Socorro.

Tendo em vista que a maioria dos potenciais doadores em nosso meio encontrava-se em Pronto Socorro e em UTI, deve haver uma conscientização a respeito do tema e treinamento adequado dos profissionais desses setores.

Essas ações são necessárias para obter uma abordagem efetiva da família dos pacientes, o que poderia trazer um aumento substancial no número de captações corneanas. ${ }^{17}$

Um estudo de 1998, realizado na Central de Captação de Órgãos da Unicamp, mostrou que nosso país possui uma das menores taxas mundiais de recusa familiar da doação de órgãos. ${ }^{24}$ Assim, uma abordagem ativa da família por parte dos profissionais de saúde poderia trazer um grande aumento no número de transplantes realizados.
$\mathrm{Na}$ literatura pesquisada ${ }^{21}$, em $81,7 \%$ dos potenciais doadores, a captação da córnea não foi realizada. Um número alto, mas ainda inferior aos 99,3\% encontrados no presente estudo.

A discrepância entre o número de potenciais doadores e o número de reais doadores foi levantada por muitos autores. ${ }^{8,16,17,25,26,27}$. A influência da equipe médica seria um dos principais fatores. Sua desinformação $0^{8,16,25,28}$ e despreparo, ${ }^{8,28}$ com conseqüente falência da abordagem da família seriam, em grande parte, os responsáveis pelo número ainda baixo de doações. ${ }^{26}$ Nesse sentido, destaca-se a importância de uma melhoria no conhecimento ensinado nas escolas médicas a respeito de transplantes..$^{25}$

Outros aspectos seriam relacionados à população, como a desinformação, fatores socioeconômicos (educação, estado civil, local de residência), a causa da morte ${ }^{27}$ e obstáculos legais e religiosos. ${ }^{8}$ A burocracia e a demora na captação são motivos de negação da doação. ${ }^{25}$ Por esse motivo, é importante a integração entre as equipes de captação e os profissionais de saúde de cada setor para que a informação do óbito e de doadores em potencial não tenha atrasos. ${ }^{23}$

\section{CONCLUSÃO}

O número de córneas doadas é muito pequeno quando comparado ao número de potenciais doadores. Neste estudo, dos 302 potenciais doadores apenas dois efetivamente doaram.

As principais causas base de óbito dos potenciais doadores foram neoplasias malignas, afecções cardíacas, afecções pulmonares, acidentes vasculares encefálicos e politrauma.

Os setores de maior prevalência de potenciais doadores foram o Pronto Socorro e a UTI geral.

A maior causa de exclusão de doadores foi septicemia, seguida por linfoma ativo disseminado e leucemia.

\section{AGRADECIMENTOS}

Agradecemos a todas as pessoas e instituições que, direta ou indiretamente, contribuíram para a elaboração deste trabalho.

\section{ABSTRACT}

Purposes: To quantify the potential cornea donors at the University Hospital Evangélico of Curitiba, comparing them with real donors and separate them by hospital units where they were attended; to verify their major base causes of death; to evidence the more prevalent criteria for exclusion whenever the donation was not possible. Methods: Retrospective descriptive study, based on handbooks and death certificates of deaths occurred between April and July of 2006 at the University Hospital Evangélico of Curitiba. Criteria for the donation exclusion were researched by analyzing: death cause and base cause of death, among others parameters. Results: 516 handbooks were analyzed. Stillbirth and up to 2 years old newborns and unidentified patients were excluded amounting a sample of 466 patients. 302 (64.8\%) were considered potential donors, $164(35.2 \%)$ not donors. Amongst 302 potential donors, only two donations were performed. This amount represents $0.7 \%$ of possible donations. The main base cause of death was malignant neoplasia (29.8\%). The majority of potential donors died at the Emergency Room (22.2\%), followed by the General Intensive Care Unit (10.5\%). The identified exclusion criteria were: Septicemia (87.2\%), spread active lymphoma (4.3\%), leukemia (3.7\%), death due to unknown cause (3.0\%), active viral encephalopathy (1.2\%), and hepatitis C ( $0.6 \%)$. Conclusion: Compared to the potential cornea donors, the actual amount of corneas donation is quite modest.

The sector of major prevalence of potential donors was the Emergency Room. The main base cause of death was neoplasia. The major cause for the exclusion of potential donors was septicemia.

Keywords: Tissue Donors, Transplantation, Cause of Death, Eye Banks, Cornea. 


\section{REFERÊNCIAS}

1. Arensten JJ. Laibson PR. Surgical management of pseudophakic corneal edema: Complications and visual results following penetrating keratoplasty. Ophthalmic Sug. 1982;13:371-3.

2. Kanski JJ. Oftalmologia Clínica. 5a ed. Rio de Janeiro: Elsevier; 2004.

3. Acedo JT. Queratoplastias y queratoprotesis. Barcelona: Edikamed; 1992.

4. Belfort Jr R. Ceratoplastias e ceratectomia. In: Belfort Junior R, Kara José N, editores. Córnea; clínica-cirúrgica. São Paulo: Roca; 1996. p. 493-504.

5. Lindiquist TD, McGlothan JS, Rotkis WM, Chandler JW. Indications for penetrating Keratoplasty: 1980-1988. Cornea. 1991;10(3):210-6.

6. Farge EJ, Silverman ML, Khan MM, Wilhelmus KR. The impact of state legislation on eye banking. Arch Ophtalmol. 1994;112:180-5.

7. Rodrigues AM, Sato E. Conhecimento e atitude da população do Hospital São Paulo sobre doação de córneas. Arq Bras Oftalmol. 2002 Nov/Dez;65(6):637-40.

8. Alves MR, Crestana FP, Kanatani R, Cresta FB, José NK. Doação de córneas: opinião e conhecimento dos médicos intensivistas do complexo Hospital das Clinicas da Faculdade de Medicina da Universidade de São Paulo. Ver Méd (São Paulo) 1997;76:315-9.

9. Loewenstein A, Rahmiel R, Varssano D, Lazr M. Obtaining consent for eye donation. Isr J Med Sci. 1991;27:79-81.

10. Associação Brasileira de Transplantes de Órgãos. (ABTO), São Paulo: Associação; Registro Brasileiro de Transplantes. Disponível em: http://www.abto.org.br

11. Saude.pr.gov.br [homepage na internet]. Curitiba: Secretaria Estadual da Saúde do Paraná; c2003- [atualizada constantemente; acesso em 2007 Jan 03]. Central de Transplantes do Paraná [aproximadamente 2 telas]. Disponível em: http://www. saude.pr.gov.br/Transplante/

12. Saude.gov.br [homepage na internet]. Brasília: Ministério da Saúde; c1997 [atualizada constantemente; acesso em 2006 Dec 27]. Lista de espera [aproximadamente 2 telas]. Disponível em: http://dtr2001.saude.gov.br/transplantes/

13. Resolução - RDC n ${ }^{\circ} 347$ da Anvisa, de 02 de dezembro de 2003 publicado no D.O.U de $03 / 12 / 2003$

14. Saude.pr.gov.br [homepage na internet]. Curitiba: Secretaria Estadual de Transplantes do Paraná; c2003- [atualizada constantemente; acesso em 2006 Mar 10]. Manual de Transplantes

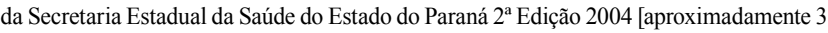
telas]. Disponível em: http://www.saude.pr.gov.br/Transplante/index.html
15. Eye Bank Association of America. Medical Standards. Washington, DC: Eye Bank Association of America, 2003.

16. Diamond AG, Campion M, Mussoline JF, D'Amico RA. Obtaining consent for eye donation. Am J Ophthalmol. 1987; 103:198-203.

17. Wiederhold C, Wilhelm F, Duncker GI, Bredhorn T. Investigations on the cornea donation at the Martin Luther-University Halle-Wittenberg. Klin Morratsbl Augenheilkd. 2001 Aug;218(8):557-61.

18. Geissler A, Paoli K, Maitrejean C, Durnd-Gasselin. Rates of potential and actual cornea donation in general hospital: impact of exhaustive death screenin and surrogate phone consent. Transplantation Proc. 2004:36;2894-5.

19. Beck RW, Gal RL, Mannis MJ, Holland EJ, Cavanagh HD, Foulks GN, et al. Is donor age an important determinant of graft survival? Cornea. 1999;18:503-10.

20. Mannis MJ, Holland EJ, Beck RW, Belin MW, Goldberg MA, Gal RL, et al. Cornea Donor Study Group - cornea donor study group -Clinical profile and early surgical complications in the Cornea Donor Study. Cornea. 2006;25(2):164-70.

21. Lucena AR, Cantanhede TMI, Mahon M, Cunha F, Cavalcanti R. Perfil geral dos potenciais doadores de córneas na cidade do Recife - PE. Rev bras oftalmol. 2000 Abr:59(4):249-53.

22. Bernardes Filho R, Guedes GB, Duarte MCB, Maiushi ACM, Moreira H. Avaliação dos potenciais doadores de córnea no Hospital de Clínicas da UFPR. Arq Bras Oftalmol. In press 2006.

23. McGough EA, Chopek MW. The Physician's role as asker in obtaining organ donations. Transplant Proc. 1990;22:267-72.

24. Ferreira U, Fregonesi A, Scafi CRF, Bachega EB, Lima ML, Netto Júnior NR. Doação de órgãos: qual é a realidade? J bras Urol. 1998 Jan/Mar;24(1):19-22.

25. Rodrigues AM, Sato E. Entendimento dos médicos intensivistas sobre o processo de doação de córneas. Arq Bras Oftalmol. 2003 Jan/Fev;66(1).

26. Mack JR, Mason P, Mathers WD. Obstacles to donor eye procurement and their solutions at the University of Iowa. Cornea. 1995;14:249-52.

27. Krieglstein TR, Neubauer AS, Welge-Lüssen U, Priglinger S, Kampik A, Priemer F. Cornea donation. Factors influencing consent. Ophthalmologe. 2001 Jun;98(6):545-9. 28. Gonzales SM, Maia M, Vicente LS, Arrata KM, Konmann RB, Moreira H. Papel do médicos intensivistas no processo de doação de córneas em Curitiba. Arq Bras Oftalmol. 1996 Ago;59(4). 